\title{
LAS FOTOGRAFÍAS DE LA ESCUELA NORMAL: CULTURA Y DETONANTES DE LA MEMORIA INSTITUCIONAL ESCOLAR
}

\author{
María Guadalupe Escalante Bravo \\ Benemérita y Centenaria Escuela Normal del Estado de San Luis Potosí, Mexico \\ escalu62@yahoo.com.mx
}

\begin{abstract}
RESUMEN
Las fotografías, el acervo antiguo, el archivo histórico y una colección de objetos y materiales educativos son los elementos que conforman el patrimonio histórico institucional, huellas de la tarea sustantiva que la Escuela Normal del Estado de San Luis Potosí en México ha desarrollado por 169 años: la formación de profesores y profesoras de educación básica. Este trabajo expone, en una primera parte, resultados de un proyecto institucional para conservar, clasificar y catalogar fotografías sobre la institución y los actores que coincidieron en ella; en otra, la utilización de las fotografías como objetos detonantes de la memoria a través de la historia oral, en forma específica, los significados que le otorga una maestra durante su permanencia en la institución como estudiante y posteriormente como profesora, a las actividades cotidianas (prácticas, normas sobre la formación docente...) que se realizaban en la institución, características de la cultura de una institución formadora de docentes.
\end{abstract}

Palabras claves: Fotografías. Cultura. Historia oral.

\section{PHOTOGRAPHS OF NORMAL SCHOOL: CULTURE AND DETONANTES OF SCHOOL INSTITUTIONAL MEMORY}

\begin{abstract}
The photographs, the old collection, the historical archive and a collection of objects and educational materials are the elements that make up the institutional historical heritage, traces of the substantive task that the Normal School of the State of San Luis Potosí in Mexico has developed for 169 years: the training of teachers of basic education. This work exposes, in a first part, results of an institutional project to conserve, classify and catalog photographs about the institution and the actors that coincided in it; in another, the use of photographs as detonating objects of memory through oral history, specifically, the meanings given by a teacher during her stay at the institution as a student and later as a teacher, to daily activities (practices, norms on teacher training ...) that were carried out in the institution, characteristics of the culture of a teacher training institution.
\end{abstract}

Keywords: Photographs. Culture. Oral history.

\section{FOTOGRAFIAS DA ESCOLA NORMAL: CULTURA E DETONANTES DA MEMÓRIA INSTITUCIONAL ESCOLAR}

\section{RESUMO}


As fotografias, a antiga coleção, o arquivo histórico e uma coleção de objetos e materiais educativos são os elementos que compõem o patrimônio histórico institucional, vestígios da tarefa substantiva que a Escola Normal do Estado de San Luis Potosí no México desenvolveu por 169 anos: a formação de professores do ensino básico. Este trabalho expõe, numa primeira parte, resultados de um projeto institucional para conservar, classificar e catalogar fotografias sobre a instituição e os atores que nela coincidiram; em outro, o uso de fotografias como detonadoras de objetos da memória através da história oral, especificamente, os significados dados por uma professora durante sua permanência na instituição como estudante e posteriormente como professora, nas atividades cotidianas (práticas, normas sobre formação de professores ...) que foram realizadas na instituição, características da cultura de uma instituição de formação de professores.

Palavras-chave: Fotografias. Cultura. História oral.

\section{PHOTOGRAPHIES DE L'ÉCOLE NORMALE: CULTURE ET DÉTONANTS DE MÉMOIRE INSTITUTIONNELLE SCOLAIRE}

\section{RÉSUMÉ}

Photographies, patrimoine ancien, archives historiques et une collection d'objets et de matériaux sont les éléments qui composent le patrimoine institutionnel, des traces de tâche de fond que l'École normale de l'Etat de San Luis Potosi au Mexique a mis au point pour 169 ans : la formation des enseignants de l'éducation de base. Cet article présente dans une première partie, les résultats d'un projet institutionnel pour préserver, classifient et des photographies de catalogue sur l'institution et les acteurs ont convenu qu'il; dans un autre, l'utilisation de photographies en mémoire déclenche des objets à travers l'histoire orale, en particulier, les significations qui donne un enseignant lors de son séjour dans l'institution comme un étudiant et plus tard comme enseignant, aux activités quotidiennes (pratiques, règles relatives à la formation des enseignants ...) qui ont été faits dans l'établissement, les caractéristiques de la culture d'une institution de formation des enseignants.

Mots-clés: Photographies. Culture Histoire orale.

\section{INTRODUCCIÓN}

En el presente documento se expone el trabajo que sobre el patrimonio histórico educativo se realiza en la Escuela Normal de San Luis Potosí, México a partir de los documentos, libros, objetos y fotografías que la institución ha logrado conservar en más de 169 años de historia. El proyecto más reciente se avocó a la preservación, catalogación y difusión de las fotografías como testimonios de la cultura escolar de una institución formadora de profesores y profesoras. La consulta y utilización de las fotografías como objeto de estudio se expone a través de la historia oral, se recuperan relatos de la estancia de una profesora normalista en la escuela en los que se 
evidencian rasgos de la cultura escolar de la institución, si bien pueden distinguirse cambios, es innegable la continuidad de otros.

Realizado en la fase de generalización del Programa de la Fundación de la Red de Archivos Históricos de las Escuelas Normales que inicio a nivel nacional en el año 2008, el inicio del proceso de organización del archivo histórico de la Escuela Normal de San Luis Potosí en el año 2010, fue el primer paso para el reconocimiento y valoración del patrimonio histórico de la institución En mayoría de las escuelas normales que participaron en este programa la organización del archivo se centró en los documentos, no es el caso del archivo de la Escuela Normal de San Luis Potosí ya que, a este aparte de los documentos, se le reconocieron dos anexos, uno bibliográfico y otro, fotográfico. (ARTEAGA y CAMARGO, 2014, p. 162).

La organización de los documentos del AHBECENE se clasificaron en los siguientes rubros: gobierno, administración académica, personal docente, personal administrativo y alumnos; el documento más antiguo es un recado en el que una estudiante pide a su padre que le compre botines, con fecha de 1863. Este documento es importante porque muestra la existencia de estudiantes mujeres, en una época en la que aún no se había fundado la Escuela Normal para profesoras, y que algunas de las jóvenes que estudiaban magisterio pertenecían a familias con recursos económicos. Los documentos más recientes de este archivo se ubican en el año 1950. El archivo fotográfico y el acervo antiguo fueron dos acciones que quedaron pendientes en ese momento. Dos años después se diseñaron e implementaron proyectos que incluían tareas de conservación, clasificación y catalogación para crear condiciones óptimas para su consulta e investigación.

El primer proyecto se llevó a cabo en el año 2014, se centró en el acervo antiguo, Patrimonio y Educación: los libros didácticos como objetos de cultura escolar, este tuvo como objetivos, por una parte, desde la perspectiva patrimonial, el tratamiento, catalogación y digitalización de algunos libros y por otra, la investigación a partir del análisis de libros de cuatro materias (Pedagogía, Economía doméstica, Higiene escolar y Geografía) del plan de estudios en la formación de profesores y profesoras que se desarrolló en el periodo histórico del Porfiriato (18761911). El objetivo fue conocer cómo los libros del acervo antiguo contribuyeron a la formación de los profesores y profesoras, insertos en una cultura escolar particular, y tratando de responder a las exigencias particulares de la sociedad de una época. Los resultados del proyecto se concretaron en dos productos: en cuanto a la valoración del patrimonio, la digitalización de 97 libros que se 
pueden consultar en la página de internet institucional; y sobre la investigación, un libro en el que se exponen las características de las materias mencionadas. Fue el inicio de la investigación sobre la cultura escolar de la institución a partir de uno de los elementos del patrimonio histórico educativo.

El segundo proyecto "El Patrimonio Histórico Educativo de la BECENE: las fotografías como detonantes de la memoria institucional" implementada en el año 2015 tuvo objetivo reconstruir la memoria de la BECENE a partir de las fotografías sobre la formación de los profesores y profesoras, sus actores, sus espacios, sus prácticas y objetos como artefactos históricos que dan cuenta de la cultura institucional y puedan aportar a la historiografía de la educación de la entidad a partir de su recuperación, preservación, difusión e investigación.

Las investigaciones sobre la fotografía es una temática que posee un amplio estado del arte y por lo tanto existen una amplia diversidad en las perspectivas y alcances desde las cuales se estudian. Zaida Lobato (s/f) hace un análisis sobre las diferentes perspectivas de estudio que se han utilizado en el uso de las fotografías, la primera que identifica es su utilidad como ilustraciones en investigaciones que han fundamentado otro tipo de fuentes, estas de alguna manera sostienen los nuevos conocimientos producidos en la historiografía reconoce el papel que tienen las fotografías para innovar en el plano de la información y del conocimiento. En este caso el valor de la fotografía se limita a su apoyo en investigaciones que utilizan otras herramientas. Al respecto Burke (2005) señala que en frecuentes ocasiones la imagen se utiliza como un elemento complementario a la utilización de otras fuentes, a veces solamente para ilustrar el contenido de una investigación, en otras ocasiones puede realizarse un análisis de las imágenes, pero no a tal grado de que pueda ser por sí solo dar respuestas o plantearse nuevas cuestiones. Señala que, en la historia de la fotografía, esta fue utilizada como auxiliar de la historia. No tuvo un papel central ya que sobre ella se planteaba el problema de dar o no crédito a las imágenes y en caso de que así fuera, se discutía hasta qué punto.

Algunos de los investigadores que empezaron a considerar las imágenes como documentos históricos como Huizinga (1872-1945) y Burckhardt (1818-1897) basaran sus descripciones e interpretaciones de la pintura de Italia y los países bajos en las pinturas de artistas de Rafael o Van Eyck, el último al respecto calificaba las imágenes y los monumentos como "objetos a través de los cuales podemos leer las estructuras del pensamiento y representación de una determinada época" (BURKE, 2005, p. 13). Compartían esta tendencia historiadores como 
Frances Yates (1899-1891), Gilberto Freyre (1900-1987), Robert Levine, Philippe Aries (19141982), Michelle Vovelle y Maurice Agulhon. Finalmente, en los años ochenta del siglo XX, Simon Schama se hizo famoso por la utilización de testimonios visuales en estudios que abarcan desde la investigación de la cultura holandesa del siglo XVIII hasta un estudio de las actitudes occidentales ante el paisaje durante varios siglos (BURKE, 2005).

Uno de los elementos que son considerados en el análisis de documentos históricos es el contexto, en el caso de la fotografía, hasta con este, es necesario tener cuidado ya que no siempre puede conocerse el origen de los modelos, los fotógrafos y la composición de los escenarios. También se afirma que la textura de la fotografía también transmite un mensaje, de ahí que se consideré que la fotografía es un objeto histórico (BURKE, 2005). El mismo autor sostiene que son particularmente valiosas porque son testimonios de la cultura material del pasado, por lo que es necesario realizar una crítica aguda de las fuentes si se somete a estas a un duro careo (BURKE, 2005).

En cuanto a las fotografías como objeto histórico y su relación con la memoria para Eulalia Collelldemont (2010) los recuerdos y los relatos son acciones que se detonan en las personas cuando visitan un museo pedagógico al observar objetos, libros, muebles y fotografías de la época que les tocó vivir, en este caso relatos y recuerdos son elementos de la memoria pedagógica. Si las fotografías sobre una escuela muestran, además, de objetos, relaciones, prácticas, entonces las memorias podrían exponer rasgos de una cultura escolar. Zaida Lobato (s/f) coincide en que las fotografías son artefactos materiales que pueden provocar el recuerdo, por ello son consideradas como objetos dignos de sostener la memoria y la identidad de una comunidad y al evocar el pasado, las fotografías también establecen una relación con el presente "las fotografías congelan gestos, situaciones, momentos y por ello sirven para perpetuar el recuerdo. Se convierten en memoria para el individuo y para una comunidad" (ZAIDA, s/f, p. 27).

\section{PATRIMONIO}

De acuerdo con Viñao (2011) si la noción de patrimonio se adjudica a un grupo social o comunidad especifica en un momento y tiempo determinado le otorga a este grupo social la conciencia de propiedad y de valor; por una parte, el sentimiento de propietario es inherente al deseo de valorar, resguardar y proteger, se convierte en un lugar de memoria; "algo a recordar y 
que nos haga recordar" (VIÑAO, 2011, p. 135), y cuando algo lo asumimos como nuestro, Bonfil (1999, p. 18) señala que:

Los objetos hechos por "nosotros" tienen, necesariamente, un significado que compartimos, porque son resultado de nuestra actividad productiva (fabrilidad) y significativa. Es decir, hacemos los objetos y al mismo tiempo les otorgamos un significado en el contexto propio de nuestra visión del mundo (que forma parte de la matriz de nuestra cultura).

De ahí que el patrimonio se considere como la representación de valores y significados propios del grupo y de la sociedad en la que están insertos. En este sentido, como un elemento de identidad y de identificación de una profesión.

En este sentido si asumimos que en este trabajo estamos hablando de un grupo social especifico, los formadores de docentes y la formación de docentes, en ambos, se reconocen prácticas, representaciones, creencias, discursos, acciones y objetos relacionados con esta tarea. Además, tarea que se realizado por largo tiempo, en periodos específicos de la historia del estado y del país. Identificar, resguardar, proteger y valorar los aspectos mencionados de una institución es un medio para conocer la cultura de una institución, de comprender los significados que otros, en otro tiempo le dieron a la tarea que sigue realizando en una escuela normal, formar profesores y profesores.

Hernández (en GONZÁLEZ; PAGÉS, 2005) asume que el término patrimonio está aún en un proceso de construcción y deconstrucción, sin embargo, al no considerarlo como un medio o recurso para conocer la historia, sino como la historia evidenciada, "es la pervivencia y aquello que queda visible del pasado y que desde el presente se le otorga valor. Por todo ello está en constante evolución, en constante cambio" (HERNÁNDEZ en GONZÁLEZ; PAGÉS, 2005, p. 57). En este trabajo, uno de los propósitos es reconocer el valor simbólico de las ideas de los hechos y de las situaciones educativas de los profesores y estudiantes de fines del siglo XIX y principios del siglo XX en una escuela formadora de profesores y profesoras.

El concepto de patrimonio cultural para su operativización está sustentado en cuatro acciones: estudio, preservación, uso y difusión. De estas cuatro tareas, la institución priorizó, debido a las condiciones de los documentos y los libros, la preservación. En el año de 2012, con la idea de conservar los documentos que ya se encontraban en mal estado se iniciaron dos procesos, por una parte, estaba la preservación física de los documentos, por otro, la digitalización del AHBECENE. Ambos se realizaron, los documentos se encuentran resguardados y se sigue 
trabajando en su catalogación; también se ha digitalizado el 90\% de los documentos. En el Acervo antiguo se inició un proceso similar y actualmente se encuentran digitalizados 97 libros con la finalidad de que puedan ser consultados en la página WEB de la institución, con esta acción también se inicia la difusión del patrimonio de la institución. Están pendientes dos acciones, la catalogación de objetos y materiales de laboratorio y de imprenta; y las fotografías que dan cuenta de la historia de la institución, específicamente esta tarea tenía características complejas para realizar las tares mencionadas (recuperación, preservación, catalogación y estudio).

\section{CULTURA ESCOLAR}

Si las fotografías como objetos históricos pueden detonar la memoria y el recuerdo, la pregunta aquí es qué recuerdo cuando veo fotografías de una institución con la cual se tuvo se mantiene relación como profesor, como trabajador o como estudiante. En el caso de una escuela, las fotografías muestran personas, relaciones, pero también acciones y objetos relacionados con lo que ahí se hace y se vive.

Julia Dominique (2010) define a la cultura escolar como un conjunto de prácticas y normas que definen conocimientos a enseñar y conductas a inculcar, en un conjunto de prácticas que permiten la transmisión de esos conocimientos y la incorporación de esos comportamientos; normas y prácticas coordinadas a finalidades que pueden variar según las épocas (finalidades religiosas, sociopolíticas o simplemente de socialización. Las fotografías muestran la consolidación de prácticas, normas e interacciones que configuran las características del profesor que se pensaba socialmente y que se concretizaban en la Escuela Normal del estado de San Luis Potosí en el periodo de fines del siglo XIX a la mayor parte del siglo XX.

\section{LAS FOTOGRAFÍAS}

La institución posee fotografías que dan cuenta de las actividades sociales, culturales, académicas y políticas de sus actores en diferentes épocas, pocas del siglo XX y la mayoría del siglo XX, éstas se encuentran en diferentes escenarios. Los motivos pueden ser múltiples, uno de ellos es la falta de un edificio propio para las escuelas normales en el siglo XIX lo que ocasionó que las instituciones (desde 1868, coexistieron dos escuelas normales, una para profesoras y otra 
para profesores) se mudaran continuamente, en el caso de la escuela normal para varones hasta en cinco ocasiones. Así podemos encontrar fotografías de las instituciones normalistas en revistas, en bibliotecas públicas y en el seminario conciliar. En el caso del seminario, se debe a que la institución normalista ocupó este edificio durante los periodos revolucionario y posrevolucionario (1914-1948) hasta que, en 1949, en el centenario de su fundación se le otorgó a la institución un edificio con características propias de una escuela normal.

A partir de recientes estudios sobre la Escuela Normal de San Luis Potosí se han recuperado en forma digital fotografías de diferentes épocas, aunadas a las que ya existían en la institución se contabilizan un más de 2000. Una acción que podría incrementar el número de fotografías es la aportación que podrían hacer los profesores y profesoras egresadas de la institución y la localización y recuperación, aunque sea en forma digital de las fotografías que se encuentren en otros espacios.

El cuerpo académico Historia, educación y formación docente propuso y trabaja en un proyecto que planteó como objetivos la realización de cinco tareas, a) recuperación de fotografías; b) digitalización; c) clasificación y catalogación; d) difusión; y e) estudio. Tiene como finalidad última que a partir de la generación de este conocimiento se transite a su uso en las aulas, como recurso didáctico. La pertinencia y utilidad del proyecto se centró en cuatro ámbitos, por una parte, la re construcción de la memoria visual, el conocimiento sobre la cultura, de la institución, por otra como aportación a la historiografía de la educación en el estado y a nivel nacional, con este proyecto se continuaría con la difusión del patrimonio histórico educativo institucional y finalmente poner a disposición de investigadores y alumnos, fuentes primarias, en el último caso, que fortalecerían la relación entre la investigación y la enseñanza de la historia de la educación.

La mayor parte de las 2200 fotografías se encontraban en la institución, pero otras se recuperaron en forma digital de otros espacios como el seminario conciliar, edificio ocupado por la Normal del Estado por más de cuarenta años, los originales se conservan en la biblioteca pública "Ricardo B. Anaya. La segunda tarea fue la digitalización de las fotografías, las cuales ya se encuentran en formato que permite su clasificación, los datos mínimos que se consideraron fue la fecha aproximada o exacta según lo permitiera el soporte de la fotografía; el lugar tentativo donde se llevó a cabo la actividad, el evento o actividad a qué se refiere y un cuadro de observaciones que puede considerar algunos datos del hecho. En última parte han participado profesores que laboran 
en la institución y que tuvieron relación o ascendientes con personas de la determinada época. Quedan pendientes dos tareas: la difusión y la investigación a partir de ellas.

La multiplicidad de tareas que asumían los estudiantes en la Escuela Normal de las prácticas que se fueron solidificando durante los años de historia de la institución, algunas se convirtieron en tradiciones como el festejo anual para celebrar el aniversario de la fundación. Otras muestran la historia de la institución como la existencia de la casa hogar para señoritas, el cual tenía como propósito otorgarles hospedaje a quienes venían a estudiar de lugares alejados de la capital del estado, lugar donde se encuentra la institución.

Fotografía 1- Estudiantes de magisterio en la casa hogar de la Escuela Normal.

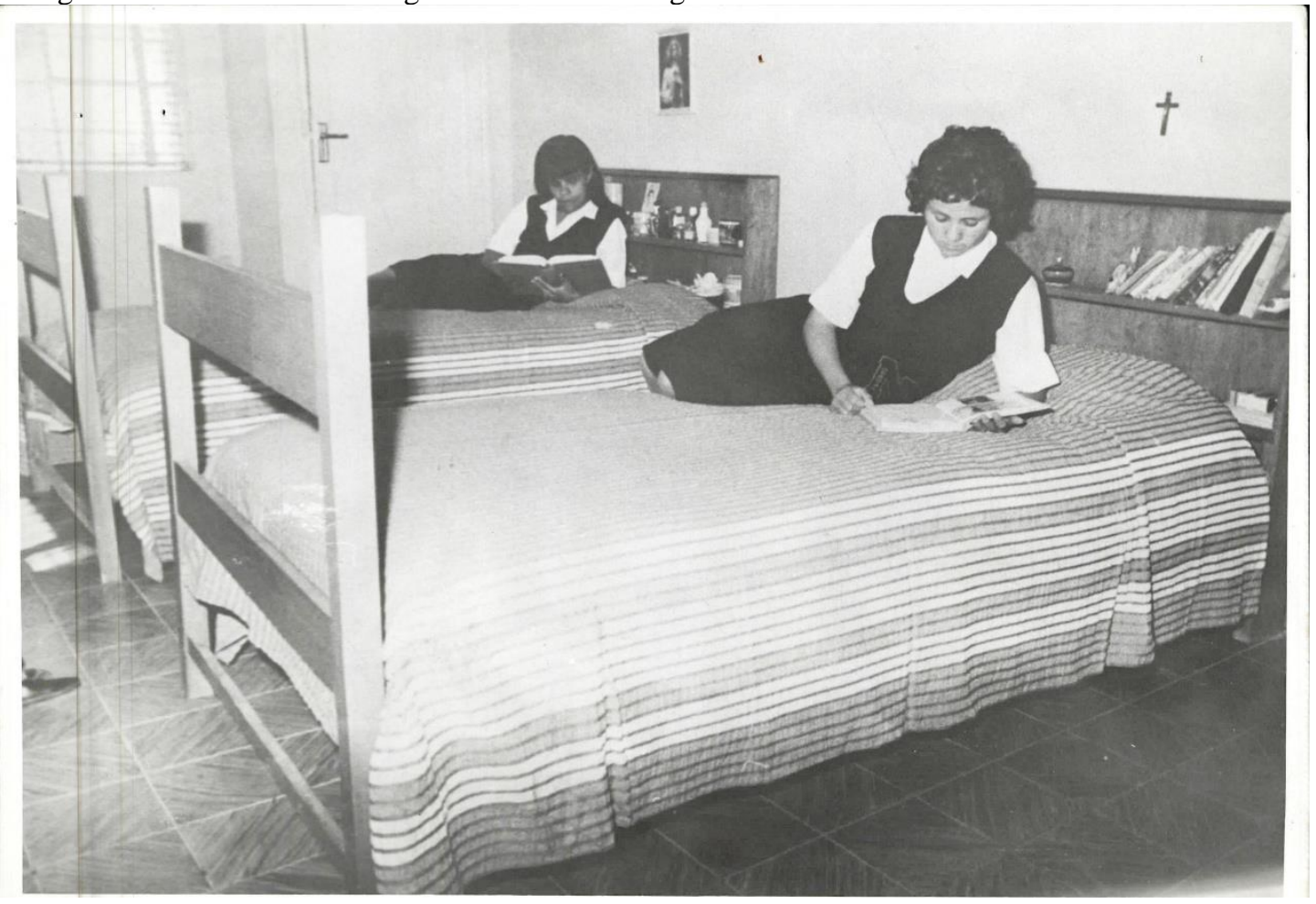

Fuente: AHBECENE.

La finalidad última era la concreción de estas prácticas en las escuelas primarias de ahí que la idea de la formación del profesor incluía conocimientos de diferentes asignaturas y con el saber profesional como pedagogía y metodología. Una de las características del plan de estudios de la Escuela Normal de San Luis Potosí desde finales del siglo XIX y hasta mediados del siglo XX fue la diferenciación de género, así existían creencias que se explicitaron en normas y prácticas para mujeres y para hombres, en cursos como economía doméstica y trabajos manuales. Las 
prácticas en la formación de profesoras y profesores podrían clasificarse de acuerdo al propósito que tenían en la cultura escolar, algunas como los honores a la bandera cada lunes se convirtió en un ritual, desde la idea de Angulo y Salazar (2010, p. 306) de que este tipo de actividades "dan certidumbre y consolidad cierto sentido de orden en el caos", y aunque no se visualicen beneficios directos desde la perspectiva de Terrence y Allan citados por Angulo y Salazar (2010, p. 306) otorgan "un sentido de seguridad e identidad común y le asignan un significado a las actividades mundanas".

Otras prácticas están relacionadas con el ser del maestro, es decir, con su identidad como integrante de un grupo social, desde la idea de Giménez (s/f, p. 1) de que "nuestra identidad solo puede consistir en la apropiación distintiva de ciertos repertorios culturales que se encuentran en nuestro entorno social, de grupo o en nuestra sociedad". Un maestro de educación primaria debería saber y aplicar su saber en danza, teatro, trabajos manuales, deportes, actividades culturales de país y de la región. Debería saber e inculcar el amor patrio, ser un ejemplo en conducta y comportamiento.

Tabla I. Clasificación de fotografías.

\begin{tabular}{|c|c|}
\hline PRÁCTICAS & $\begin{array}{l}\text { COMPORTAMIENTOS O } \\
\text { CONDUCTAS }\end{array}$ \\
\hline $\begin{array}{ll}\text { - } & \text { Grupo de danza folklórica } \\
\text { - } & \text { Coro normalista } \\
\text { - } & \text { Obras de teatro } \\
\text { - } & \text { Poesía coral } \\
\text { - } & \text { Declamación individual } \\
\text { - } & \text { Oratoria }\end{array}$ & $\begin{array}{l}\text { Actividades artísticas como parte de la idea } \\
\text { de educación integral, responsabilidad del } \\
\text { maestro de educación primaria. } \\
\text { Generalmente se impartían en clubes o } \\
\text { talleres vespertinos }\end{array}$ \\
\hline $\begin{array}{ll}\text { - } & \text { Honores a la bandera } \\
\text { - } & \text { Juramento a la bandera }\end{array}$ & $\begin{array}{l}\text { Estas prácticas tienen como propósito } \\
\text { fortalecer el comportamiento cívico de los } \\
\text { estudiantes de profesorado, los cuales } \\
\text { posteriormente serán extendidos en las } \\
\text { escuelas primarias. } \\
\text { El primero se realiza los lunes antes de } \\
\text { iniciar las labores docentes. } \\
\text { El segundo es un acto que realizan los niños } \\
\text { de tercer grado de todo el país. }\end{array}$ \\
\hline $\begin{array}{ll}- & \text { Pintura } \\
\text { - } & \text { Tejido } \\
\text { - } & \text { Guitarra } \\
\text { - } & \text { Trabajos manuales }\end{array}$ & $\begin{array}{l}\text { Las actividades manuales son } \\
\text { complementarias a la formación de profesor. } \\
\text { Durante mucho tiempo estuvieron } \\
\text { relacionadas con las diferencias de género. }\end{array}$ \\
\hline
\end{tabular}




\begin{tabular}{|c|c|}
\hline $\begin{array}{ll}\text { - } & \text { Carreras atléticas } \\
\text { - } & \text { Futbol } \\
\text { - } & \text { Voleibol } \\
\text { - } & \text { Basquetbol }\end{array}$ & $\begin{array}{l}\text { Actividades físicas como parte de la idea de } \\
\text { educación integral, también era una área } \\
\text { responsabilidad del maestro de educación } \\
\text { primaria. }\end{array}$ \\
\hline $\begin{array}{ll}\text { - } & \text { Altar de muertos. } \\
\text { - } & \text { Piñatas. } \\
\text { - } & \text { Periódico mural }\end{array}$ & Prácticas de la cultura escolar. \\
\hline
\end{tabular}

Fuente: AHBECENE.

La profesora Marcela fue estudiante de la Escuela Normal del Estado en la penúltima década del siglo XX actualmente se desempeña como profesora de la licenciatura en educación secundaria con especialidad en español en la misma institución. Durante una entrevista expone características y nociones de la formación que recibió en la Escuela Normal. Los datos que la profesora comparte están relacionados directamente con la cultura escolar de una escuela formadora de profesores y profesoras:

De mi época como estudiante recuerdo un ambiente agradable, un ambiente de trabajo en el que los maestros estaban al pendiente de la formación docente; es decir, desde mi punto de vista era un circulo muy cerrado de los docentes que trabajaban en la institución dado que yo creo, no sé, exactamente la cantidad de docentes que laboraban, pero, puedo decir que eran aproximadamente cincuenta, posiblemente son demasiados.

Había caravanas de cultura, nos acercaban a la cultura con actores, al parecer era por medio del ISSSTE en donde tuvimos la oportunidad de tener espectáculos con actrices como Susana Alexander, o bien con bailarines como Roberto D’Amico, actores como Germán Valdés recuerdo que era en el auditorio de la institución, no con las remodelaciones que ahora tiene, sino como estaba inicialmente, siempre contamos con este tipo de actividades. Es innegable el compañerismo, cabe destacar que de los 42 compañeros que ingresamos fueron los mismos 42 que egresamos; el grupo estaba compuesto por 28 mujeres y 14 hombres, éramos cuatro grupos de educación primaria, el grupo a, b, c y d; había de preescolar. La diferencia que había en cuanto al trabajo de escolar y primaria fue que cada año ingresaba una generación de primaria y de preescolar era por generación, cada que terminaba una generación y entraba otra. Es decir, era cada cuatro años. 
Fotografía 2- Grupo de danza.

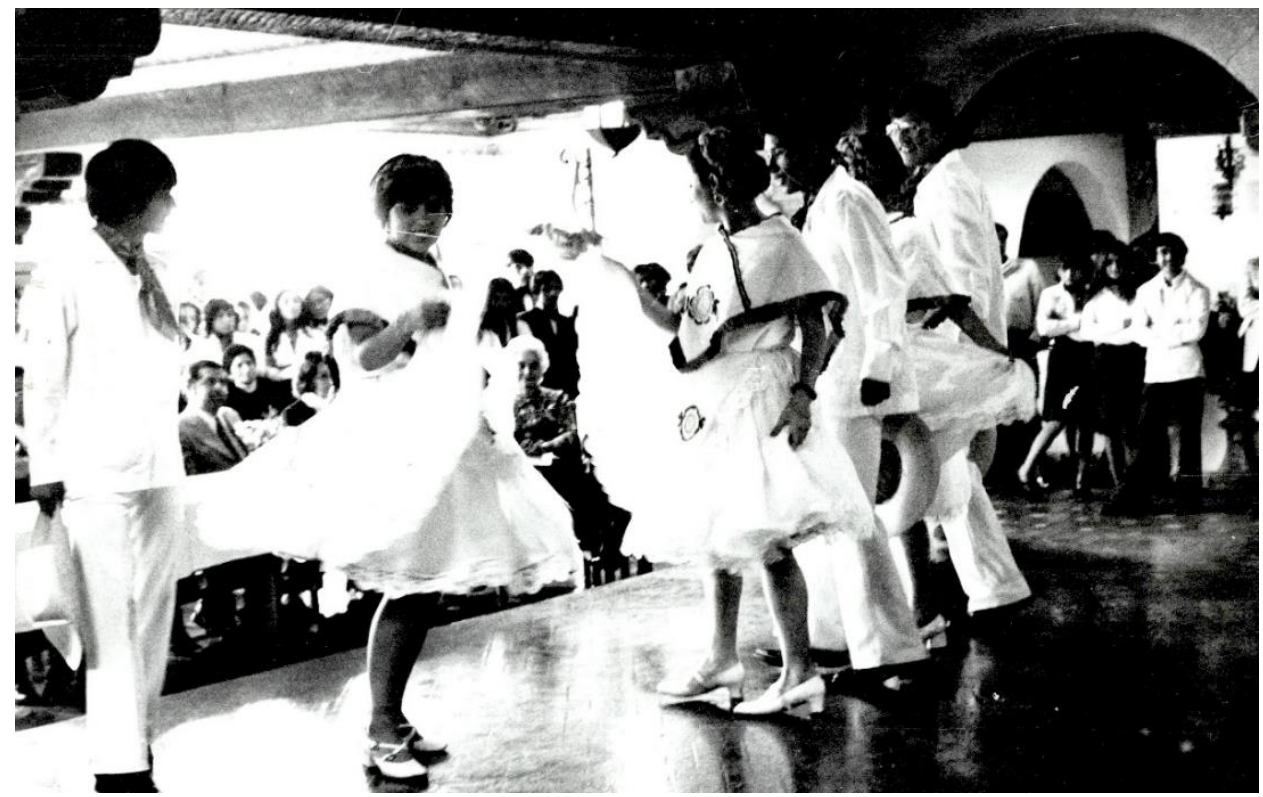

Fuente: AHBECENE.

Se nos supervisaba el uniforme, era una cosa muy curiosa nos llamaban la atención, pero logramos entender que todo era parte formativa; teníamos música, yo egresé orgullosamente de esta institución como profesora de educación primaria, teníamos clase de música, nos daban danza, teatro, educación física porque los maestros teníamos el compromiso de trabajar todas las áreas para el desarrollo del ser humano., matemáticas, español, inglés, formación cívica y ética. Era una regla, una norma, que hasta el día de hoy prevalece, portar el uniforme, los lunes todo el día, si tenías educación física o actividades culturales como teatro tenías que traer tus aditamentos adicionales para portar el uniforme adecuadamente. Eran características, las observaciones que nos hacían las maestras, algunas de ellas en paz descansen, otras todavía hemos tenido oportunidad de verlas, nos hacían observaciones respecto a nuestra conducta dentro y fuera de la escuela, reitero, repito que logramos entender que todo era formativo más que una imposición.

Había clubes de guitarra clásica, rondalla, fotografía, tuvimos la oportunidad de trabajar la madera y hacer jugueteros; utilizamos el encuadernado con un maestro que todavía vive, es inspector de una zona de educación primaria, el maestro Heriberto Miranda quién nos enseñó a hacer este tipo de manualidades. En danza el maestro Raúl Turrubiartes, en educación física, el maestro Galdino Grimaldo.

Fui muy interesante el primer año de ingreso a esta institución cuando por jóvenes, por estar platicando en las gradas que todavía se conservan en el patio central del edificio. Llegamos corriendo al aula y ya muy preocupados porque el maestro no nos dejó entrar; nuestros compañeros salieron angustiados cuando concluye la hora clase, consternados porque el profesor les había llamado severamente la atención, pasan unos minutos y después de esa preocupación por los que no entramos y la mortificación delos de adentro por la llamada de atención, resulta que el maestro se había equivocado de grupo. No se me olvida esa anécdota.

Los maestros estaban al pendiente de lo que realizábamos, no nos cuidaban efectivamente y si me gustaba mucho el hecho de que veníamos a las actividades sin necesidad de ser obligatorias, creo esa parte hay que seguir trabajando en la actualidad, porque los alumnos todo lo ven como una obligación si comprendieran que el hablar de usted, el cumplir normas y reglas es la parte formativa que nosotros aquí en la escuela eso es lo que estamos enseñando, guiando a los alumnos para que ellos a su vez, para que el día de mañana ellos

Rev. Iberoam. Patrim. Histórico-Educativo, Campinas (SP), v. 5, p. 1-14, e019003, 2019 
lo hagan frente a los grupos de educación básica con la finalidad de que sus alumnos comprendan que es la parte formativa no impositiva, eso cuesta mucho trabajo.

En el discurso de la maestra se perciben características de lo que debe ser un maestro, o maestra en este caso, justificando o asumiendo el significado de algunas prácticas como el uso del uniforme. Es explicita la idea de que los profesores deben saber muchas cosas, porque la finalidad última es la formación de los niños de educación primaria. Se distinguen lazos entre el grupo de compañeros de generación de la maestra a pesar de los años transcurridos, se recuerda a maestros y maestras a través de sus enseñanza y reprimendas. La memoria coincide con las fotografías, es el significado de una imagen si bien como un rasgo de la formación de profesores y profesoras, el propósito que tenía danzar, bailar, hacer teatro.

\section{CONSIDERACIÓN FINAL}

El proyecto institucional para la preservación, catalogación y difusión de las fotografías de la Escuela Normal del Estado de San Luis Potosí es una parte de una aspiración mayor, tiene como finalidad la valoración de patrimonio histórico educativo institucional. El trabajo con las fotografías dio lugar a la identificación, desde la mirada de la cultura escolar, las prácticas que conformaron una profesión y, por lo tanto, las características de un profesor idóneo: conocimientos de cultura general, de actividades artísticas, deportivas, además, de una actitud ejemplar dentro y fuera de la escuela.

Los beneficios se han ampliado, uno de ellos es el conocimiento sobre los cambios y continuidades de las prácticas y normas que han redundado en la construcción de una identidad grupal, en este caso, de los profesores y profesoras que se forman en esta institución. La historia oral, en este trabajo, a partir de los testimonios de una profesora normalista comparte sus vivencias como estudiante entrelazando, en el mismo relato, sus creencias y acciones como docente.

\section{BIBLIOGRAFÍA}

ANGULO HERNÁNDEZ, Lilian Nayive; LEÓN SALAZAR, Aníbal Ramón. Los rituales en la escuela. Una cultura que sujeta al currículo. Educere [en línea], 14, junio/diciembre, 2010. Disponible en: http://www.redalyc.org/articulo.oa?id=35617102007. Fecha de consulta: 29 agosto 2018. 
ARTEAGA, Belinda; CAMARGO, Siddharta, La organización de los archivos históricos de las escuelas Normales de México y el aporte de su contenido a la historia de la educación. Perfiles Educativos [en línea], XXXVI, 2014. Disponible en: http://www.redalyc.org/articulo.oa?id=13231362010. Fecha de consulta: 8 agosto 2018.

BONFIL, Guillermo, 1999-2000. Nuestro patrimonio cultural: un laberinto de significados en Revista Mexicana de Estudios Antropológicos, vols. XLV-XLVI, p. 22, 16-39. Sociedad Mexicana de Antropología, México, p. 27.

BURKE, Peter. Visto y no visto. El uso de la imagen como documento histórico. Barcelona, 2005 Disponible en: http://www.scribd.com/Insurgencia. Fecha de consulta: 8 agosto 2018.

COLLELLDEMONT, Eulalia. La memoria visual de la escuela. Educatio Siglo XXI, v. 28, n. 2, p. 133-156, 2010.

GIMÉNEZ, Gilberto, La cultura como identidad y la identidad como cultura, México, Instituto de Investigaciones Sociales de la UNAM. (s/f). Disponible en: http://perio.unlp.edu.ar/teorias2/textos/articulos/gimenez.pdf. Fecha de consulta: 8 agosto 2018.

GONZÁLEZ, Neus; PAGÉS, Joan. La presencia del patrimonio cultural en los libros de texto de ESO en Cataluña. Departamento de Didáctica de las Ciencias Sociales, Facultad de Ciencias de la Educación, Universidad Autónoma de Barcelona, 2005. Disponible en: http://www.investigacionenlaescuela.es/articulos/56/R56_5.pdf. Fecha de consulta: 8 agosto 2018.

JULIA, Dominique. La culture scolaire comme objet historique. Paedagogica Historica. International Journal of the History of Education (Suppl. Series, v. I, coord. A. Nóvoa, M. Depaepe e E. V. Johanningmeier, 1995, p. 353-382 (Tradução de Gizele de Souza). Revista Brasileira de História da Educação, n. 1, jan./jun. 2001. Disponible en: http://periodicos.uem.br/ojs/index.php/rbhe/article/view/38749/20279. Fecha de consulta: 8 agosto 2018.

VIÑAO, Antonio. Memoria, Patrimonio y Educación, Revista Historia de la Educación - RHE, Porto alegre, v. 15, n. 34, p. 31-62, enero-abril. 2011.

ZAIDA LOBATO, Mirna. Memoria, historia e imagen fotográfica: los desafíos del relato visual. XVI Jornadas de investigación de la Facultad de Ciencias Humanas, anuario n. 5, s/f. Facultad de Ciencias Humanas. UNLPam. p. 25-38.

Recebido em: 30 de agosto de 2018 Aceito em: 17 de dezembro de 2018 